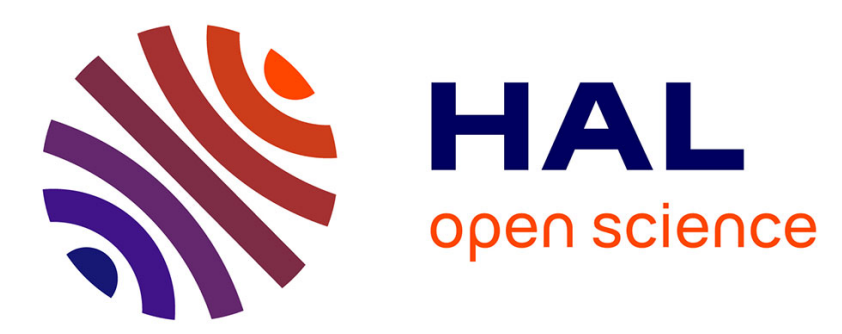

\title{
Antibacterial Cellulose Nanopapers via Aminosilane Grafting in Supercritical Carbon Dioxide
}

Bruno Jean, Clémentine Darpentigny, Cécile Sillard, Mathilde Menneteau, Eugénie Martinez, Pierre R. Marcoux, Julien Bras, Guillaume Nonglaton

\section{- To cite this version:}

Bruno Jean, Clémentine Darpentigny, Cécile Sillard, Mathilde Menneteau, Eugénie Martinez, et al.. Antibacterial Cellulose Nanopapers via Aminosilane Grafting in Supercritical Carbon Dioxide. ACS Applied Bio Materials, In press, 10.1021/acsabm.0c00688 . hal-03003201

\section{HAL Id: hal-03003201 https://hal.science/hal-03003201}

Submitted on 24 Nov 2020

HAL is a multi-disciplinary open access archive for the deposit and dissemination of scientific research documents, whether they are published or not. The documents may come from teaching and research institutions in France or abroad, or from public or private research centers.
L'archive ouverte pluridisciplinaire HAL, est destinée au dépôt et à la diffusion de documents scientifiques de niveau recherche, publiés ou non, émanant des établissements d'enseignement et de recherche français ou étrangers, des laboratoires publics ou privés. 


\title{
Antibacterial cellulose nanopapers via aminosilane
}

\section{grafting in supercritical carbon dioxide}

\author{
Clémentine Darpentigny, ${ }^{\dagger, t, \xi, ¥}$ Cécile Sillard, ${ }^{\ddagger}$ Mathilde Menneteau, ${ }^{\S}$ Eugénie Martinez, ${ }^{\S}$ Pierre \\ R. Marcoux, ${ }^{\S}$ Julien Bras, ${ }^{,}, \#$ Bruno Jean, ${ }^{\dagger}$ and Guillaume Nonglaton ${ }^{\S}$, * \\ ${ }^{\dagger}$ Univ. Grenoble Alpes, CNRS, CERMAV, 38000 Grenoble, France \\ ${ }^{\ddagger}$ Univ. Grenoble Alpes, CNRS, Grenoble INP, LGP2, F-38000 Grenoble, France \\ ${ }^{\S}$ Univ. Grenoble Alpes, CEA, LETI, MINATEC Campus, F-38054 Grenoble, France
}

KEYWORDS Cellulose nanofibrils; Supercritical carbon dioxide; Functionalization; Antibacterial; Aminosilane.

ABSTRACT In this work, we present an innovative strategy for the grafting of an antibacterial agent onto nanocellulose materials in supercritical carbon dioxide $\left(\mathrm{scCO}_{2}\right)$. Dense cellulose nanofibril (CNF) nanopapers were prepared and subsequently functionalized in supercritical carbon dioxide with an aminosilane, $N$-(6-aminohexyl)aminopropyltrimethoxysilane (AHA-PTMS). Surface characterization (X-ray photoelectron spectroscopy, contact angle, zeta potential analysis) evidenced the presence of the aminosilane. Results show that the silane conformation depends on the curing process: a non-polycondensed conformation of grafted silane with the amino groups facing outwards was favored by curing in an oven while the curing step performed 
in $\mathrm{scCO}_{2}$ yielded $\mathrm{CNF}$ structures with the alkyl chain facing outwards. The grafted nanopapers exhibited antibacterial activity and no antibacterial agent was released into the media. Furthermore, these materials proved to benefit from a low cytotoxicity. This study offers a proof of concept for the covalent grafting of active species on nanocellulose structures and the control of aminosilane orientation using a green and controlled approach. These newly designed materials could be used for their antibacterial activity in the biomedical field. Thus, perspectives for topical administration and design of wound dressing could be envisaged.

\section{GRAPHICAL ABSTRACT}
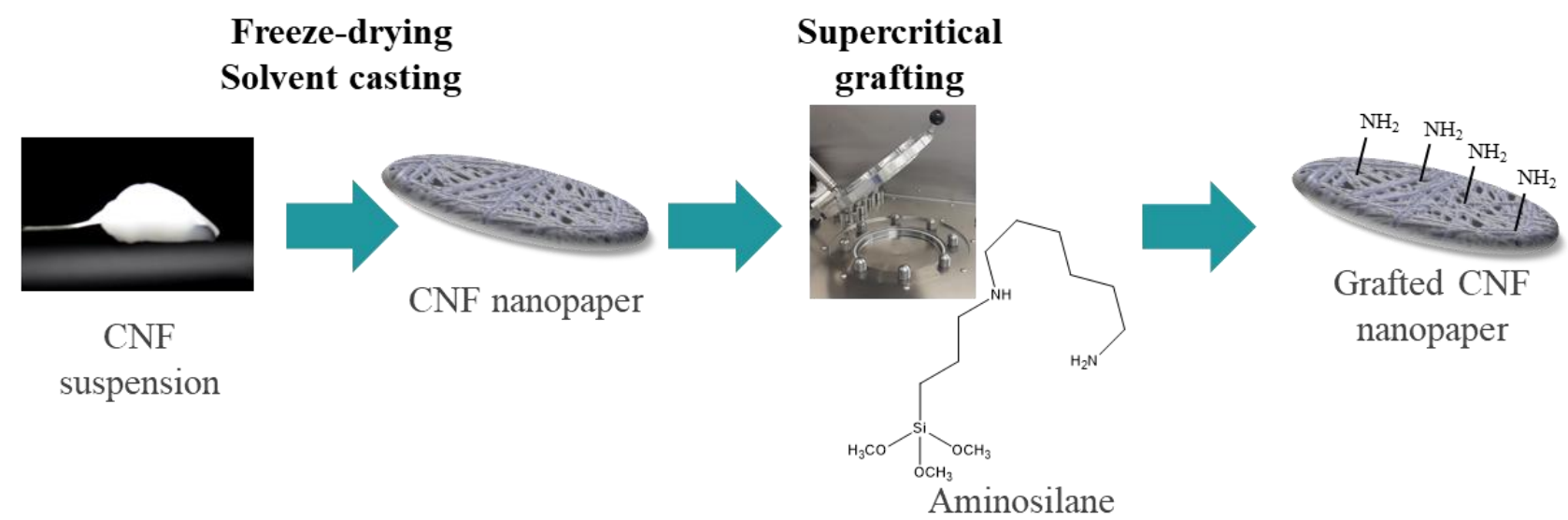

\section{INTRODUCTION}

Cellulose nanofibrils (CNFs) are nanoscale cellulose particles extracted from the biomass by chemical and/or mechanical treatments in the form of semi-crystalline, long and entangled fibers. They have gained tremendous interest in the search for sustainable materials. Their renewable, biodegradable and bio-based nature provides an attractive alternative to fossil-based resources. Their isolation and characterization methods have been actively investigated and reported in many reviews. ${ }^{1-3}$ Moreover, their commercial availability has increased the interest from both the 
academic and industrial communities since CNFs are or could be used in many applications such as cosmetics, healthcare, electronics, ${ }^{4-5}$ papermaking ${ }^{6-7}$ or the medical industry. ${ }^{8-10}$ As far as biomedical applications are concerned, their cytocompatibility has been studied and no evidence of toxicity has been reported. ${ }^{9,11-12}$ Jorfi and Foster ${ }^{8}$ have discussed the advances of the use of nanocellulose for medical implants, tissue engineering, wound healing and drug delivery. Specifically, the major advantages of cellulose such as good mechanical properties, versatility, biocompatibility and renewability can be harnessed for the design of sustainable and bio-based wound dressing materials. However, cellulose does not exhibit intrinsic antimicrobial properties. Strong research efforts were therefore dedicated to the functionalization of nanocellulose to confer new antibacterial and antifungal activities to cellulose-based materials.

Impregnation of antimicrobial agents can be performed using fast and simple procedures, as illustrated in a previous study with the impregnation of thymol. ${ }^{13}$ However, strategies based on non-covalently bound drug suffer from some limitations such as the possible release of the drug in the environment and the short lifespan of the material. For a long-term lasting and contact activity, covalent bonding of antimicrobial agents onto the CNFs should be favored. For that purpose, antimicrobial properties can be added to the nanocellulose particles through chemical grafting. Because of the availability of hydroxyl groups, several modification strategies can be employed to modify the surface of nanocellulose, such as oxidation, esterification, polymer grafting or silanization. ${ }^{14-17}$ There is little literature available on antimicrobial activity introduced through direct grafting onto CNFs. Antimicrobial agents grafted include 2-benzyl-4chlorophenol, ${ }^{18}$ L-cysteine, ${ }^{19}$ penicillin, ${ }^{20}$ quaternary ammonium compounds, ${ }^{21}$ nisin ${ }^{22}$ or quinolinium silane salt. ${ }^{23}$ In a bio-mimicking approach, 3-aminopropyl trimethoxysilane was shown to be a good candidate to mimic the antibacterial activity of chitosan. ${ }^{24}$ Fernandes et al. 
and Saini et al. gave an insight on the antimicrobial properties of aminosilane-grafted bacterial cellulose films and CNFs nanopaper, respectively. ${ }^{24-25}$ When protonized, the amine group is thought to have antibacterial activity because of the ionic interactions with the bacterial cell wall, which loses its balance. These interactions cause a disruption in the cell wall and lead to leakage of the intracellular electrolytes and eventually to bacterial death. ${ }^{24,26-28}$ The availability of the amino groups is a requirement for antibacterial activity. Kim et al. have shown that long alkyl chains of $\mathrm{N}$-alkyl substituents enhance the antimicrobial activity by increasing the hydrophobicity. ${ }^{29}$ A recent study points out the importance of the number of amino groups and chain length on stability of the silane and grafting efficiency. ${ }^{30}$ Orientation of aminosilane is also crucial but very difficult to characterize as shown by the use of TOF-SIMS by Reverdy et al. ${ }^{31}$ Very recently, Chantereau et al. performed silanization of bacterial cellulose with two aminosilanes, the 3-aminopropyl trimethoxysilane and the (2-aminoethyl)-3-aminopropyltrimethoxysilane, in acetone and in water followed by a curing or a freeze-drying step, respectively. ${ }^{32}$ Grafting stability and limited homocondensation were achieved and attributed to the low initial concentrations of silane and the structure of the (2-aminoethyl)-3-aminopropyltrimethoxysilane which prevents the amine-catalyzed hydrolysis generally observed with aminosilanes such as (3-aminopropyl)-trimethoxysilane.

In order to prepare sustainable active materials, functionalization reactions must be preferably performed in environmentally benign solvents. Vapor deposition of silane has been heavily studied in recent years. ${ }^{33-34}$ This method of deposition is particularly interesting for the functionalization of biomaterials. ${ }^{35-37}$ However, this method is rather limited to the deposition of relatively volatile silane with high vapor pressure such as 3-aminopropyltriethoxysilane, aminopropyldimethylethoxysilane or aminopropyldiisopropylethoxysilane (calculated vapor 
pressures of 2, 237 and $5 \mathrm{~Pa}$ at $25^{\circ} \mathrm{C}$, respectively). Supercritical carbon dioxide $\left(\mathrm{scCO}_{2}\right)$ is a green solvent considered as a good alternative to organic solvents and its use presents additional advantage of easy solvent elimination, non-flammability, non-toxicity and cheapness. The low working temperature and pressure of carbon dioxide in its supercritical state allow structural preservation of fragile structures and heat-sensitive compounds. For these reasons, the supercritical technology is compatible with biomedical devices design. Moreover, its remarkable properties of zero surface tension, low viscosity and high and tunable density provide high diffusivity and high diffusion coefficients. ${ }^{38-40}$ Its use is particularly interesting for the deposition of silane with low vapor tension difficult to deposit by vapor deposition. Evidence of silanization in supercritical carbon dioxide on various inorganic substrates can be found in the literature. ${ }^{41-43}$ However, silanization of nanocellulose structures has never been performed in supercritical fluids. In the present study, the $N$-(6-aminohexyl)aminopropyltrimethoxysilane (AHA-P-TMS) molecule was chosen as a novel aminosilane to be grafted onto cellulose-based materials in $\mathrm{scCO}_{2}$ for several reasons. First, its alkyl chain length should ensure its solubility in $\mathrm{scCO}_{2}$ and, together with the two amino groups, should confer a good antibacterial activity. Second, contrary to aminopropyltrimethoxysilane, the AHA-P-TMS cannot form five membered cyclic intermediates known to catalyze the hydrolysis of the Si-O-C bonds leading to a polycondensation reaction. Indeed, the use of an aminosilane with longer alkyl chain is expected to reduce the formation of siloxane bridges by decreasing the basic behavior of the secondary amine and to hinder the intra-molecular catalysis of siloxane bond hydrolysis. ${ }^{32,44}$ In addition, the relatively low vapor pressure of AHA-P-TMS (calculated vapor pressure of $0.04 \mathrm{~Pa}$ at $25^{\circ} \mathrm{C}$ ) prevents its vapor deposition and makes the use of the $\mathrm{scCO}_{2}$ deposition very attractive. 
In this context, the AHA-P-TMS was grafted on CNF structures in $\mathrm{scCO}_{2}$ in order to develop antimicrobial materials. For this purpose, 2D dense nanopapers (NP) were prepared and functionalized. In the first part of the study, the impact of the processing conditions (time and curing) on the grafting efficiency and the grafting configuration are investigated. The second part focuses on the antibacterial properties of the functionalized nanopapers against two bacteria (Escherichia coli and Staphylococcus epidermidis). The contact activity of the nanopapers was investigated based on measurements carried out both in solid and liquid conditions. In addition,

in order to consider these new materials for the development of innovative wound dressings, ${ }^{45-46}$ preliminary results on the cytotoxicity of the newly prepared materials are reported.

\section{EXPERIMENTAL SECTION}

Materials. Cellulose nanofibrils (Exilva, type P, hemicellulose content $\sim 2.8 \%$ ) at $2 \mathrm{wt} \%$ solid content were provided by the Borregaard company and redispersed at $0.5 \mathrm{wt} \%$ in distilled water by stirring at $8000 \mathrm{rpm}$ during 5 min with an Ultra Turrax IKA T25.

Chemicals. $N$-(6-aminohexyl)aminopropyltrimethoxysilane (CAS number 51895-58-0, at 95 $\%$ purity from Gelest), tert-butyl alcohol ( $\geq 99.0 \%$, CAS number: 75-65-0, from Fisher Scientific) and toluene (CAS number 108-88-3, for analysis from Carlo Erba Reagents) were used for the experiments. Ciprofloxacin (85721-33-1, $\geq 98.0 \%$ for HPLC) was supplied by Sigma-Aldrich. Tryptic soy broth (VWR 470015-844), Mueller-Hinton broth (VWR 90003-966) prepared from powder, tryptic soy agar contact plates containing neutralizing agents (RODAC contact plates with Tween ${ }^{\circledR}$, lecithin, histidine, thiosulphate), tryptic soy agar Petri plate and Mueller-Hinton agar Petri plate (VWR 100611ZA, $90 \mathrm{~mm}$ diameter), pharmacopoeia diluent (VWR AX021314 $\mathrm{NaCl}$ peptone broth at $\mathrm{pH}$ 7) and pharmacopoeia diluent with neutralizing 
agents (Tween ${ }^{\circledR}$, lecithin, histidine, thiosulphate) were purchased from VWR Chemicals. WST-1 reagent was supplied by Roche.

Bacteria. Biosafety level 1 lyophilized strains, Staphylococcus epidermidis ATCC 14990 (KWIK-STIK 0412P) and Escherichia coli ATCC 25922 (KWIK-STIK Plus 0335X), were supplied by Microbiologics (St Cloud MN).

Nanopapers preparation. CNF nanopapers (NP) were prepared by vacuum filtration using a handsheet former (Rapid Kothen, ISO 5269-2). $400 \mathrm{~mL}$ of a CNF suspension at 0.5 wt \% was filtered through a $1 \mu \mathrm{m}$ nylon sieve at 600 mbar during 5 min. After complete water filtration, the wet sheet was dried at $85{ }^{\circ} \mathrm{C}$ under vacuum during $20 \mathrm{~min}$ in between two nylon sieves and two cardboards to prevent adhesion.

Supercritical carbon dioxide grafting. The grafting reaction was performed in a supercritical SFD-200 equipment built by SEPAREX (Nancy, France) and 31Degrees (Montauban, France). The CNF nanopapers were placed inside the pressurized chamber along with $5 \mathrm{~mL}$ of AHA-PTMS at 10 vol.\% in toluene placed in an aluminum container. The temperature was set to $50{ }^{\circ} \mathrm{C}$ and the pressure was increased to 120 bar at a speed of 20 bar.min $^{-1}$. The reaction was performed during $60 \mathrm{~min}$ to $180 \mathrm{~min}$, after which the chamber was washed during $5 \mathrm{~min}$ with $50 \mathrm{~g} \cdot \mathrm{min}^{-1}$ $\mathrm{CO}_{2}$ flow. The depressurization step was performed at 8 bar.min $^{-1}$. Covalent bonding was induced by the elimination of water molecules during a curing step of $2 \mathrm{~h}$ in an oven at $105^{\circ} \mathrm{C}$ or in supercritical carbon dioxide at $50^{\circ} \mathrm{C}, 120$ bar. After grafting, samples were stored in Petri dishes containers in a clean room environment.

Microscopy. The CNF suspension was first observed with a Zeiss Axioplan 2 optical microscope and images were recorded with an Olympus SC50 digital camera operated by the Olympus Stream software. A Dimension icon ${ }^{\circledR}$ atomic force microscope (Bruker, USA) was used 
to observe the CNF suspension in tapping mode after deposition on a mica plate and overnight drying. A silicon cantilever (OTESPA, Bruker, USA) was used for image acquisition. CNF nanopaper images were recorded with a Quanta 200 scanning electron microscope after immobilization on carbon tape and $10 \mathrm{~nm}$ carbon layer coating. At least five images of the suspension and nanopapers were recorded and image contrast adjustment and CNF size measurement were performed using the ImageJ software.

Contact angle determination. Contact angle measurements were performed using an OCA 20 DataPhysics instrument. A $3 \mu \mathrm{L}$ distilled water droplet was deposited on the surface of CNF nanopapers at room temperature. The contact angle and drop volume evolution were recorded for $90 \mathrm{~s}$ with a CCD camera. At least four measurements were performed and average values were reported.

Surface zeta potential. The surface zeta potential of $2 \mathrm{~cm} \mathrm{x} 1 \mathrm{~cm}$ oxidized silicon substrates and nanocellulose thin films was measured using a SurPASS equipment from Anton Paar GmbH (Graz, Austria). A flow of $\mathrm{KCl}\left(10^{-3} \mathrm{M}\right)$ solution, in between the samples attached to a cell was set to $100 \mathrm{~mL} \cdot \mathrm{min}^{-1}$ at a pressure of $300 \mathrm{mbar}$. The electrical potential was measured as a function of the pressure difference and was used to determine the flow potential. The zeta potential determination was based on the streaming potential and streaming current measurements.

X-ray photoelectron spectroscopy (XPS). XPS analysis was performed with a VersaProbe II spectrometer equipped with a monochromatic X-ray source at $1486.6 \mathrm{eV}$ and energy resolution of $0.5 \mathrm{eV}$. An angle of $45^{\circ}$ between the surface and the analyzer was used for photoelectrons detection. The materials were scanned to a depth of $3.6 \mathrm{~nm}$. Data were analyzed using the Multipak software. 
Contact activity assessment. All solutions and materials used were sterile or sterilized in autoclave $\left(121{ }^{\circ} \mathrm{C}, 15 \mathrm{~min}\right)$ prior use for microbiology experiments. No further sterilization than a step in $\mathrm{scCO}_{2}$ was performed for $\mathrm{CNF}$ materials before assessment of the antibacterial properties.

Minimum inhibitory concentration determination. E. coli and S. epidermidis were cultured overnight at $37{ }^{\circ} \mathrm{C}$ until they reached the exponential growth phase. A series of broth tubes (Mueller-Hinton broth) containing AHA-P-TMS concentrations in the range of 0.28 to 2.22 $\mathrm{mg} / \mathrm{mL}$ was prepared and inoculated with a standard density of the test organism. This $0.5 \mathrm{McF}$ density (measured with Densicheck, bioMérieux) was prepared from at least three isolated colonies, following the EUCAST recommendations. ${ }^{47}$ They were incubated into 96-wells microplate at $37{ }^{\circ} \mathrm{C}$ during 16 hours. The optical density at $600 \mathrm{~nm}$ of the bacterial suspension was recorded every 15 min with an Infinite-1000 Tecan microplate reader. After $16 \mathrm{~h}$ incubation, the minimum inhibitory concentration (MIC) was established as the lowest concentration of agent that prevents visible bacterial growth. Negative (sterile) and positive (no antibacterial agent) controls were performed. Tetraplicates were measured.

Assessment of antibacterial activity in liquid. CNF nanopapers were placed in microplate wells and $1 \mathrm{~mL}$ of bacterial suspension at $0.5 \mathrm{McF}$ in Mueller-Hinton nutrient broth was added. The wells were incubated at $37^{\circ} \mathrm{C}$ under shaking in an Infinite-1000 Tecan microplate reader and the optical density was recorded at $600 \mathrm{~nm}$ every $5 \mathrm{~min}$. A growth control with bacteria, nutrient broth and without CNF material and a sterility control with nutrient broth, CNF materials and without bacteria were performed and experiments were repeated twice.

Non-leaching assay. Neat and grafted materials were incubated in a pharmacopoeia diluent added with Tryptic soy nutrient broth $(1 \mathrm{~mL}$ of nutrient broth in $500 \mathrm{~mL}$ of pharmacopoeia 
diluent) for 24 hours at $37{ }^{\circ} \mathrm{C}$ under shaking at $70 \mathrm{rpm}$. The $\mathrm{CNF}$ materials were removed and $900 \mu \mathrm{L}$ of leaching solution was inoculated with $200 \mu \mathrm{L}$ of bacterial solution at a concentration of $0.5 \mathrm{McF}$. After incubation during $24 \mathrm{~h}$ at $37{ }^{\circ} \mathrm{C}$ under $70 \mathrm{rpm}$ shaking, bacterial growth was evaluated from optical density measurements at $600 \mathrm{~nm}$. A negative control was performed by adding ciprofloxacin in the leaching solution before inoculation with bacteria. The nonleaching assay was used to determine if the AHA-P-TMS was grafted or leached out of the materials. In the latter configuration, bacterial growth inhibition or bacterial concentration reduction would be observed.

Cytotoxicity assay. The cytocompatibility of the materials was assessed using the exact same protocol as the one employed in our previous work. ${ }^{13}$ NIH3T3 fibroblasts were seeded in culture wells during 24 hours. The growth medium was removed and replaced with $200 \mu \mathrm{L}$ growth medium added with AHA-P-TMS at increasing concentrations. A positive control (living) and a negative control with $10 \mathrm{mM}$ of $\mathrm{H}_{2} \mathrm{O}_{2}$ (dead) were performed. After 24 hours, the growth medium was removed and replaced with $100 \mu \mathrm{L}$ of growth medium and $10 \mu \mathrm{L}$ of WST-1 reagent. After 2 hours of incubation at $37^{\circ} \mathrm{C}$ the viability was deduced by reading the absorbance at $450 \mathrm{~nm}$ with an Infinite1000 TECAN microplate reader. Sextuplicates were performed.

To investigate the cytotoxicity of the nanocellulose materials, they were first sterilized under UV light during $15 \mathrm{~min}$. Then, two different protocols were used to probe the cytotoxicity.

Direct protocol: NIH-3T3 fibroblasts were cultured in 24-wells plate with a density of $9.10^{4}$ cells per well in $1 \mathrm{~mL}$ of growth medium in the presence of the sample to be tested. Negative (10 $\mathrm{mM}$ of $\mathrm{H}_{2} \mathrm{O}_{2}$ ) and positive (growth medium) controls were performed. The plates were incubated at $37^{\circ} \mathrm{C}$ during 24 hours, after which $100 \mu \mathrm{L}$ of WST-1 reagent was added and the viability was 
deduced after 2 hours of incubation by reading the absorbance at $450 \mathrm{~nm}$ with an Infinite-1000 TECAN microplate reader. Triplicates were performed.

Indirect protocol: extracts were obtained by placing the samples in a separate growth medium for 24 hours at $37^{\circ} \mathrm{C}$. The cells were cultured at a density of 4.5 .104 cells per well in $500 \mu \mathrm{L}$ of culture medium during 24 hours. Negative $\left(10 \mathrm{mM}\right.$ of $\mathrm{H}_{2} \mathrm{O}_{2}$ ) and positive (growth medium) controls were performed. After 24 hours, the cell culture media was replaced with the extract solution. $50 \mu \mathrm{L}$ of WST-1 reagent was added and the viability was deduced after 2 hours of incubation by reading the absorbance at $450 \mathrm{~nm}$ with an Infinite 1000 TECAN microplate reader. Triplicates were performed.

\section{RESULTS AND DISCUSSION}

Nanocellulose materials characterization. The cellulose nanofibril suspension used in this study was observed by optical and atomic force microscopy (AFM) and images are presented in Fig. 1. From optical microscopy images, it appears that the suspension is highly heterogeneous, with remaining large fibers and bundles of microfibrils. A finer analysis of the "nanosize" fraction by AFM reveals long and entangled nanofibrils with average dimensions of $25 \mathrm{~nm}$ in diameter and more than $1700 \mathrm{~nm}$ in length, thus exhibiting a very high aspect ratio. Due to entanglements between the high aspect ratio CNFs, the grey-white suspension was gel-like and viscous. These nanofibrils are semi-crystalline with a degree of crystallinity of $49 \%$, measured by ${ }^{13} \mathrm{C}$ solid-state NMR and previously reported. ${ }^{48}$ 

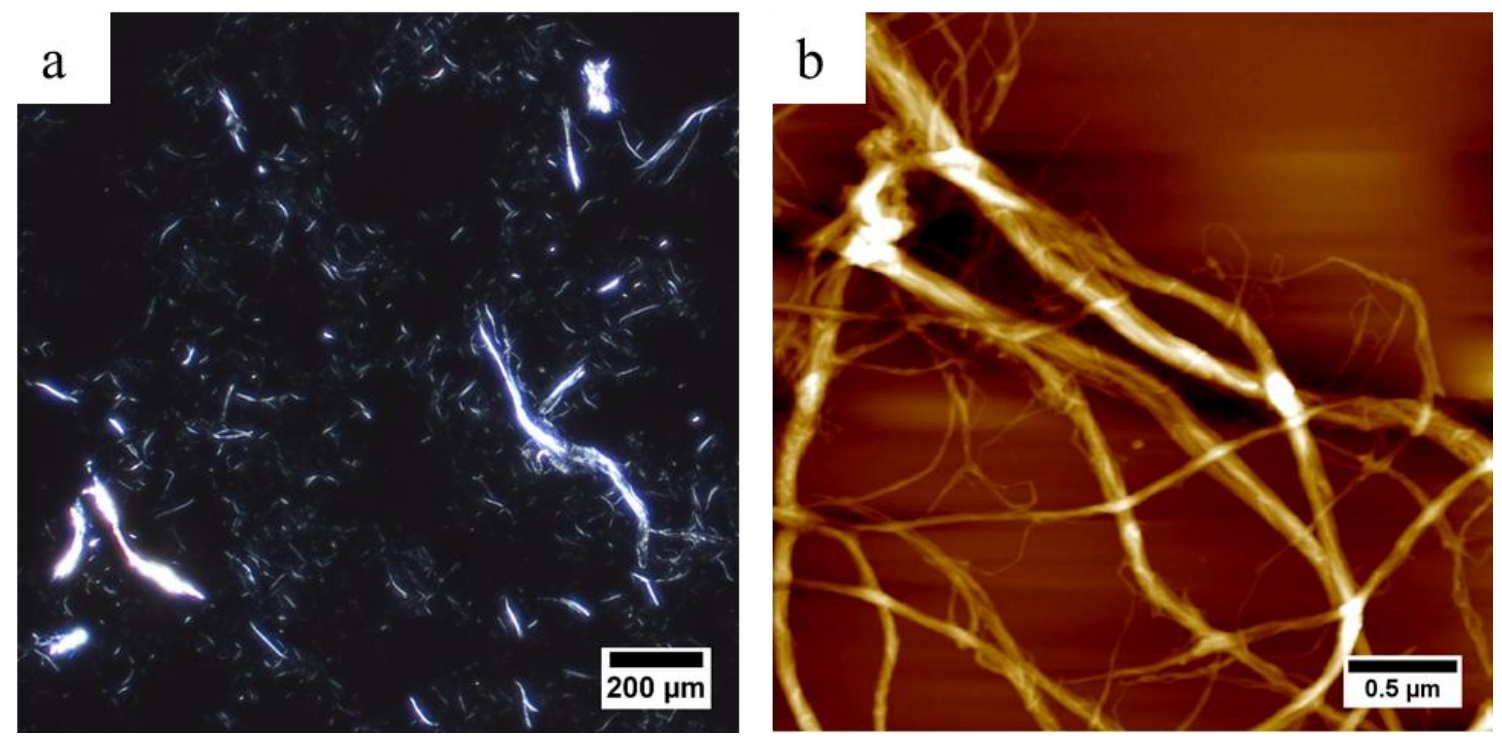

Fig. 1. Cellulose nanofibrils suspension observed from optical microscopy (a) and atomic force microscopy (b).

This CNF suspension was used to produce $150 \mathrm{~mm}$ diameter nanopapers (Fig. 2c). They were obtained after vacuum filtration of the suspension followed by vacuum drying. The suspension was filtered through a nylon sieve and the surface morphology of the nanopaper was highly dependent on the side observed (Fig. 2). The side that was in contact with the sieve during filtration presents a morphology with defects (Fig. 2a). The other side was in contact with the air during filtration and presents a smoother surface (Fig. 2b). The resulting nanopapers exhibited a thickness of $47.5 \pm 3.5 \mu \mathrm{m}$.
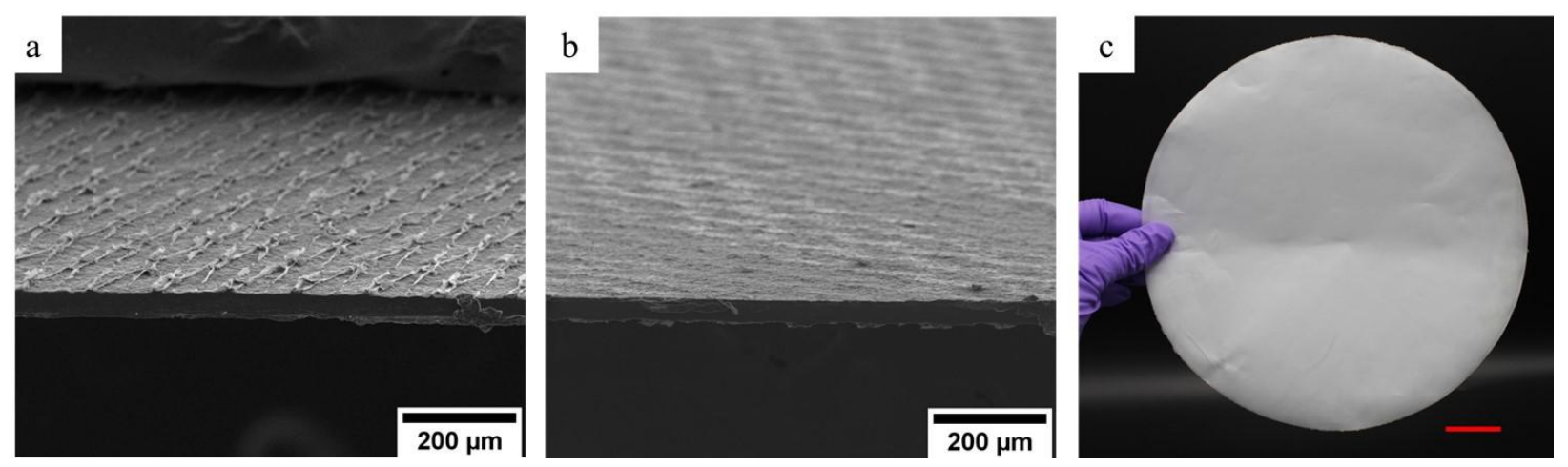
Fig. 2. Scanning electron microscopy images of nanopapers on membrane-interface (a) and airinterface (b) and photograph of a nanopaper (c). Red scale bar represents $3 \mathrm{~cm}$.

Aminosilane grafting. The grafting of AHA-P-TMS on nanopapers in $\mathrm{scCO}_{2}$ was performed at 120 bar and $50{ }^{\circ} \mathrm{C}$. The values of the different parameters (concentration, temperature, pressure, time and curing) are reported in Table 1.

Table 1. Parameters of the different AHA-P-TMS grafting conditions

\begin{tabular}{rcccc}
\hline Grafting parameters & NP-3hOv & NP-1hOv & NP-1hSc & NP-neat \\
\hline Silane concentration $(\mathbf{m M})$ & 10.4 & 10.4 & 10.4 & - \\
Temperature $\left({ }^{\circ} \mathrm{C}\right)$ & 50 & 50 & 50 & - \\
Pressure (bar) & 120 & 120 & 120 & - \\
Reaction time (h) & 3 & 1 & 1 & - \\
Curing & Oven $2 \mathrm{~h}$ at $105^{\circ} \mathrm{C}$ & Oven $2 \mathrm{~h}$ at $105{ }^{\circ} \mathrm{C}$ & $2 \mathrm{~h} \mathrm{in} \mathrm{scO}_{2}$ & -
\end{tabular}

At the end of the process, a small amount of waxy residues was recovered in the aluminum container. This shows the presence of insoluble carbamates, formed by the reaction between the amines and carbon dioxide. ${ }^{49}$ No further step of purification of the grafted materials was required after the reaction thanks to the evaporation of $\mathrm{scCO}_{2}$ when the pressure was decreased that leaves no residual solvent or free unreacted AHA-P-TMS.

Silanization of oxide surfaces is usually performed in a mixture of organic solvent and water, where formation of silanols groups by hydrolysis is initiated in bulk by the presence of water leading to polycondensation and poor control over the reaction mechanisms. ${ }^{25,50}$ Domingo et al. 
reported that monolayers of silanes can be grafted onto oxide particles in supercritical carbon dioxide, where the silane hydrolysis takes place on the surface of the materials where water is present as adsorbed molecules. ${ }^{51}$ A similar scenario is expected in the case of the grafting onto the hydrophilic surface of CNF materials for which adsorbed water molecules are naturally present at the surface. Furthermore, our process does not include critical point drying, which could result in desorbing the water molecules from the surface.

Our proposed reaction scheme of AHA-P-TMS silane grafting onto cellulose is illustrated in Fig. 3a. First, AHA-P-TMS is thought to come in contact with the CNF materials, where adsorbed water molecules are present, and to be hydrolyzed into silanols groups. The second step involves the formation of covalent bonds by condensation with the elimination of water molecules. This second step is expected to mainly occur mainly during curing.

a

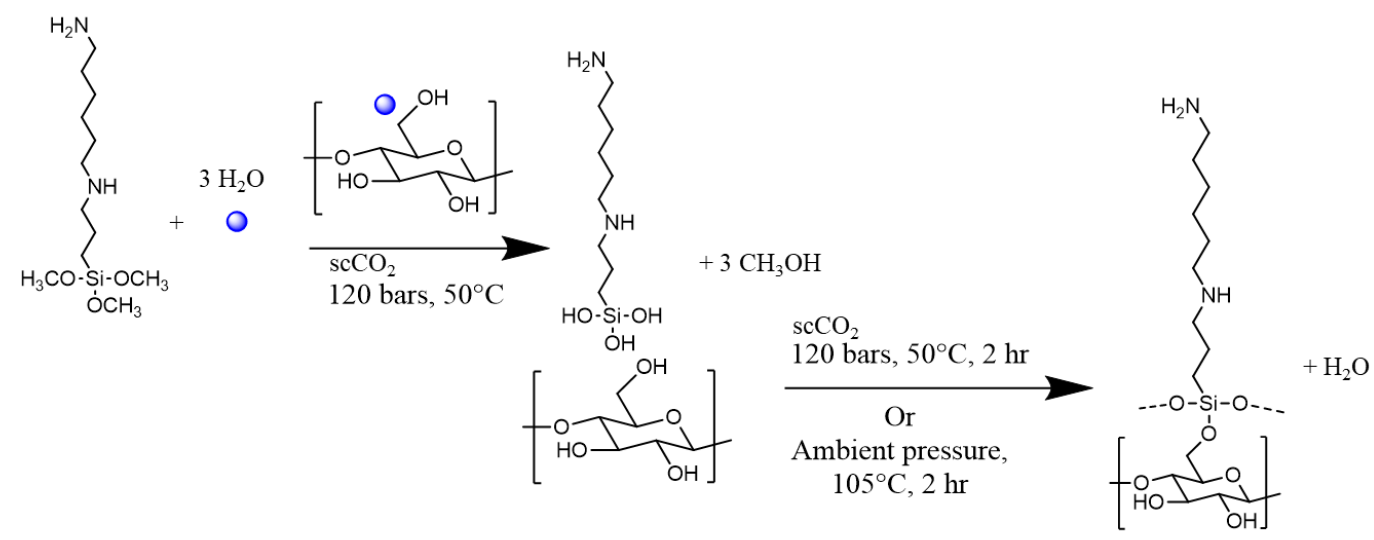

b
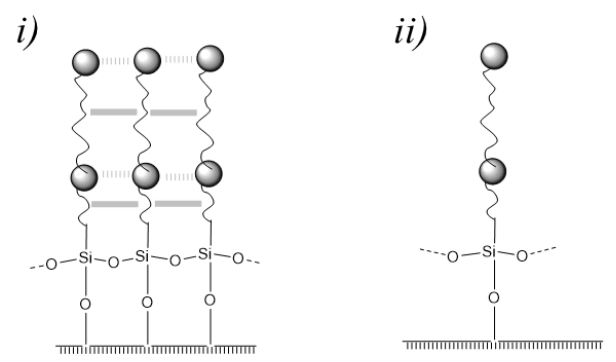

iii)

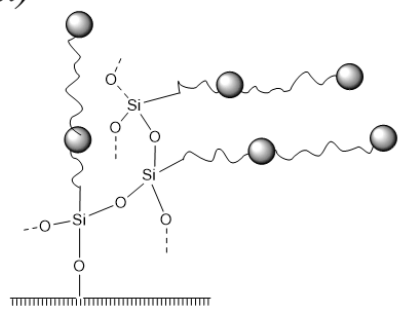

iv)

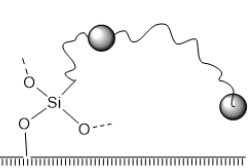


Fig. 3. AHA-P-TMS grafting steps in $\mathrm{scCO}_{2}$ reaction schematics (a) and schematic representation of the possible aminosilane conformations (i, ii, iii and iv) (b). Dashed grey lines represent H-bonds and bold grey lines represent hydrophobic interactions. Blue spheres represent water and grey spheres represent amino groups of AHA-P-TMS.

Different conformations of the silane can arise from such a reaction. They are depicted in Fig. 3b and will be referred to as (i), (ii), (iii) and (iv) in the text. (i) consists in a model selfassembled monolayer where numerous $-\mathrm{NH}_{2}$ groups are facing outwards. The second case (ii) is a conformation with lower silane density where AHA-P-TMS silane is bound to the surface with the $-\mathrm{NH}_{2}$ group facing outwards. Then in iii), polycondensated AHA-P-TMS silanes layer where the amino group, silane group or alkyl chain are facing outwards could form in case of high grafting density. A last possibility with low silane density is a conformation with the alkyl chain facing outwards, as shown in (iv).

In order to evidence the presence and the conformation of silane grafted on the nanocellulose materials, various characterizations techniques were used. The unambiguous determination of the silane conformation on the surface is often difficult. As discussed by De Monredon et al., the conformation changes with the surface density. ${ }^{52}$ At low density, molecules cover a large surface area and tend to adopt a folded conformation. At high density, molecules tend to assemble with carbon chains facing outwards. When the density is below the monolayer, molecules are nonstatistically distributed leading to the formation of islands. In their publication, De Monredon et coll. have used on one hand solid-state ${ }^{29} \mathrm{Si}$ NMR and Karl Fischer titration to produce useful information on the silica samples grafted with (3-aminoethyl)aminopropyltrimethoxy silane and UV-visible and ESR spectroscopy on the other hand to study the silane conformation. ${ }^{53}$ In our study, AHA-P-TMS silane conformation on the nano-cellulose surface was discussed based on 
the results of surface-sensitive characterization available in our lab (X-ray photoelectron spectroscopy, contact angle measurement, zeta potential measurements of macroscopic solids) in addition to the assessment of antibacterial activity. ${ }^{29} \mathrm{Si}$ solid-state NMR experiments have been carried out but the low concentration of silane at the surface did not produce useful information on the grafted surface.

An X-ray photoelectron spectroscopy (XPS) analysis was performed in order to obtain information concerning the chemical composition of the surface of neat and grafted CNF nanopapers. This technique has a sensitivity up to 0.1 at. $\%$ and analyzes the first $3-4 \mathrm{~nm}$ of the surface. The full spectrum and the corresponding elemental composition for each nanopaper are reported in Fig. 4. For the neat CNF nanopaper, carbon and oxygen are present and observed at 287 and $533 \mathrm{eV}$, respectively. The theoretical $\mathrm{O} / \mathrm{C}$ ratio is of 0.83 and, consistently, a 0.81 ratio is observed for the neat NP. For the grafted materials, the carbon content was higher, as illustrated by the decrease of the $\mathrm{O} / \mathrm{C}$ ratio to $0.63,0.67$ and 0.63 for NP-3hOv, NP- $1 \mathrm{hOv}$ and NP-1hSc, respectively. Characteristic peaks of nitrogen and silicon were observed for the grafted nanopapers at 400 and $102 \mathrm{eV}$, respectively. Such results evidence the presence of alkyl chains at the surface of the CNF nanopapers. 


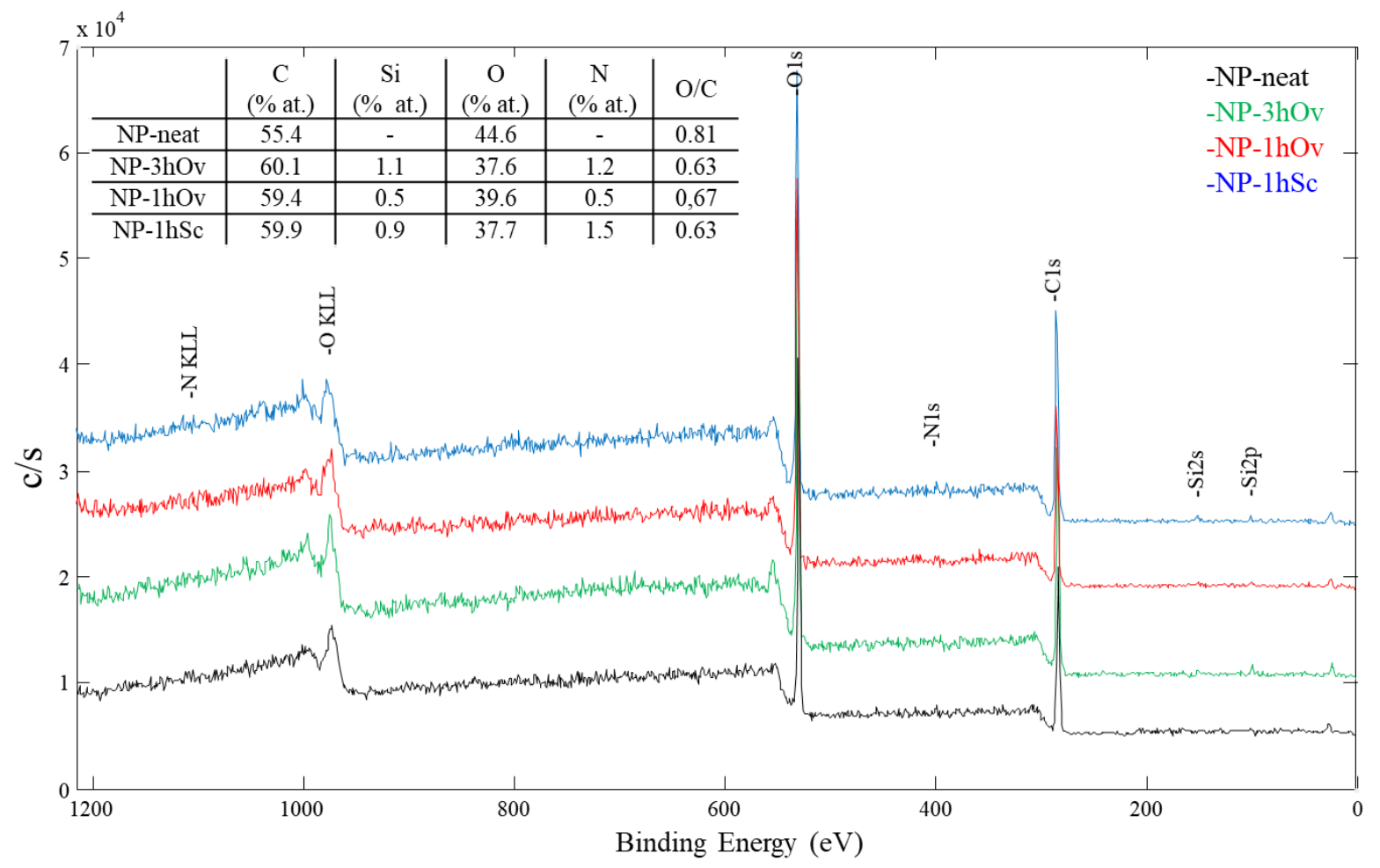

Fig. 4. XPS full spectra and elemental percentages of neat and AHA-P-TMS-grafted NPs.

The carbon 1s peak was deconvoluted and the corresponding spectra are presented in Fig. 5a. Four peaks are observed corresponding to different carbon conformations, $\mathrm{C} 1$ for carbon bonded to carbon or hydrogen, $\mathrm{C} 2$ for carbon bonded to non-carbonyl oxygen, $\mathrm{C} 3$ for carbon bonded to two non-carbonyl or a single carbonyl oxygen and $\mathrm{C} 4$ for carboxyl carbon. Their binding energies are the following: $\mathrm{C}-\mathrm{H}$ and $\mathrm{C}-\mathrm{C}(\mathrm{C} 1)$ at $284.6 \mathrm{eV}, \mathrm{C}-\mathrm{O}(\mathrm{C} 2)$ at $286.3 \mathrm{eV}, \mathrm{O}-\mathrm{C}-\mathrm{O}(\mathrm{C} 3)$ at $287.7 \mathrm{eV}$ and $\mathrm{O}-\mathrm{C}=\mathrm{O}(\mathrm{C} 4)$ at $289.0 \mathrm{eV}$. The first peak is more intense for grafted nanopapers $(23-26 \%)$ than for the neat-NP ( $8 \%$ ). This is consistent with a higher amount of C-C and C-H bonds present at the surface of the derivatized CNF NP. The carbons linked to nitrogen and silicon (C-N, C-Si) also appear at $284.6 \mathrm{eV}$. The $\mathrm{C} 1 / \mathrm{C} 3$ ratio increases from 0.4 for the neat $\mathrm{NP}$ to 2, 1.8 and 1.8 for NP-3hOv, NP-1hOv and NP-1hSc, respectively. This is evidence of an 
increase in carbon per glucose units. Such an increase gives a clear proof of the presence of the aminosilane on the surface of the CNF nanopapers.

a
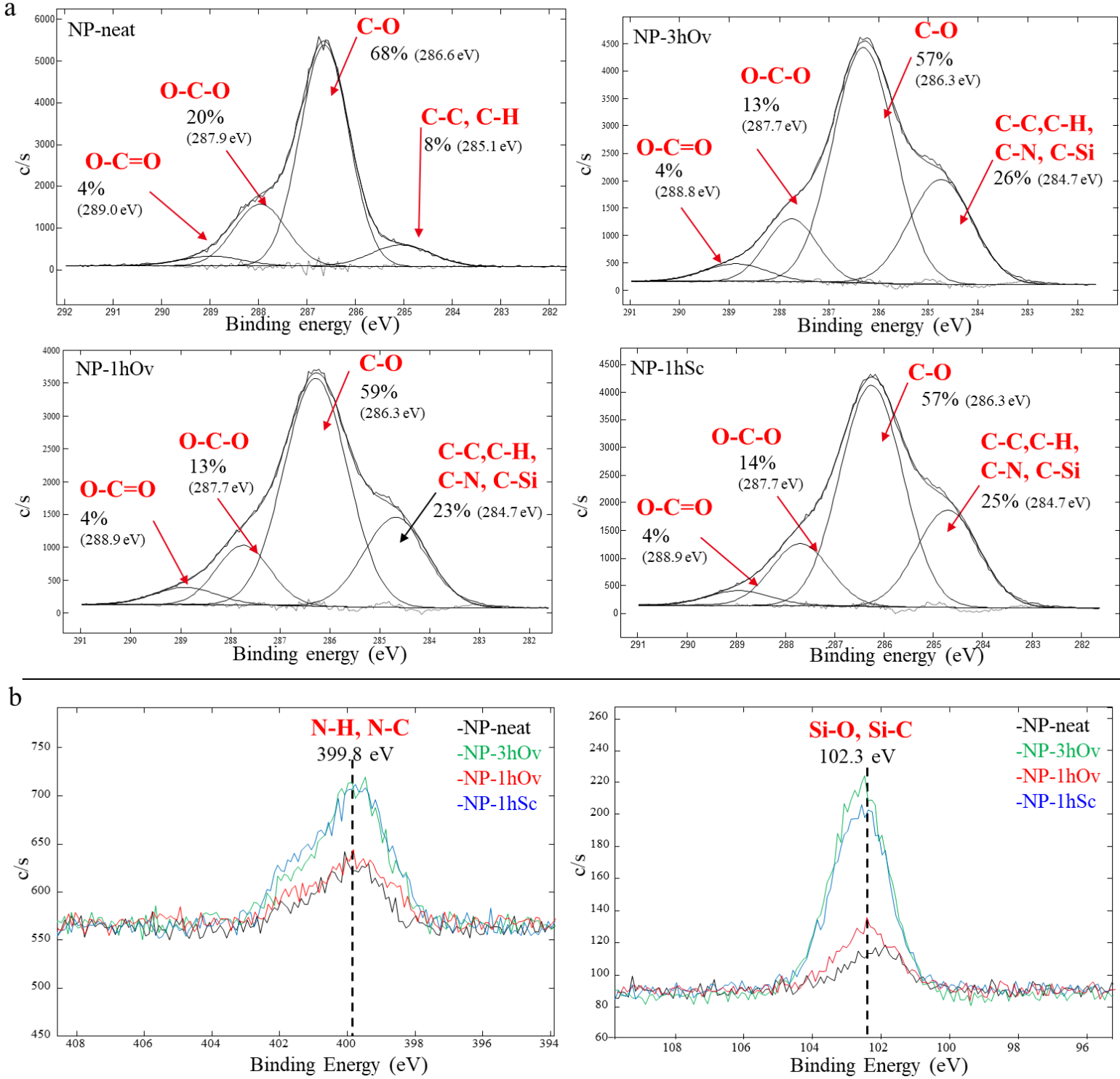

Fig. 5. XPS C 1s peaks of neat and grafted nanopapers (a) and spectra of $\mathrm{N} \mathrm{1s} \mathrm{(left)} \mathrm{and} \mathrm{Si} \mathrm{2p}$ (right) peaks of grafted nanopapers (b).

The $\mathrm{N}$ 1s and Si 2p peaks are presented in Fig. $5 \mathbf{b}$ and the corresponding elemental relative concentrations are shown in the table embedded in Fig. 4. Regarding nitrogen, Marzorati et al. have reported binding energies for terminal amines between 398.4 and $398.8 \mathrm{eV}$, for secondary 
or tertiary amines between 400.0 and $400.5 \mathrm{eV}$ and in the case of intra- or inter-molecular bonding a binding energy between 402.0 and $403.0 \mathrm{eV} .{ }^{54}$ These three peaks can be distinguished in the N1s spectrum of Fig. $\mathbf{5 b}$.

A theoretical N/Si ratio of 2:1 is expected, however, only a slightly higher amount of nitrogen compared with silicon was detected for NP3h-Ov and NP1h-Ov. For NP1h-Sc, the ratio increases to $\sim 1.7$. This is probably due to a problem of sensitivity: indeed, the concentrations of $\mathrm{N}$ and Si being very low compared to those of $\mathrm{C}$ and $\mathrm{O}$. There is also a relatively significant uncertainty on the quantitative results obtained by XPS, because the relative concentrations are calculated from tabulated sensitivity factors (obtained from standards whose composition may differ from the analyzed sample). Nevertheless, a clear increase in the intensity of the nitrogen and silicon peaks was observed after grafting for samples N3h-Ov and NP1h-sc, which is consistent with the presence of the AHA-P-TMS on the surface of the CNFs. However, the intensity of the signals is weak, showing that a low amount of silane was grafted. For sample NP1h-Ov, only a very limited grafting was achieved. Results tend to show that in the case of oven curing, an increase of the reaction time from 1 to $3 \mathrm{~h}$ allows to increase the extent of the functionalization. However, samples NP3h-Ov and NP1h-sc exhibit quite comparable N and $\mathrm{Si}$ amounts, which could suggest that curing in $\mathrm{scCO}_{2}$ is more efficient than curing in the oven and compensates for a lower reaction time.

The $\mathrm{Si} 2 \mathrm{p}$ spectrum is composed of a single peak corresponding to Si-O bonds. Yin et al. grafted an aminosilane onto cellulose nanocrystals $(\mathrm{CNCs})$ in an ethanol/water mixture (80:20 $\mathrm{v} / \mathrm{v}$ ) and observed a second peak at $101 \mathrm{eV}$, corresponding to $\mathrm{Si}-\mathrm{O}-\mathrm{Si}$ silicon bonds, which was attributed to polycondensation. ${ }^{55}$ The absence in our case of this second peak suggests that polycondensation could not have occurred. Nevertheless XPS spectroscopy is not sufficient to 
judge the degree of grafting. This must be confirmed by other techniques such as ${ }^{29} \mathrm{Si}$ solid-state NMR. In our case, ${ }^{29} \mathrm{Si}$ solid-state NMR did not produce useful information on the grafted silane presumably due the too low concentration of silane at the surface. The low grafting amount detected and the probable absence of polycondensation tend to show that the supercritical fluid technology favors the deposition of no more than a monolayer of silane. As demonstrated by Domingo et al., the use of $\mathrm{scCO}_{2}$ should prevent the occurrence of polycondensation, since due to the low water content of $\mathrm{scCO}_{2}$, the hydrolysis step can only take place at the surface of the material. ${ }^{51}$ Thus, in $\mathrm{scCO}_{2}$, the silane molecules do not hydrolyze in solution and therefore do not condensate on the material. The very low grafting amount is also likely to prevent the formation of siloxane bridges and reduces the chances to obtain self-assembled conformations (conformation (i) in Figure 3).

To get more insight into the surface grafting and silane conformation, the different samples were also characterized by water contact angle measurements. The contact angle was recorded for $90 \mathrm{~s}$ and the droplet volume was monitored to verify that it was constant and not decreasing as a result of water uptake by the CNF nanopapers. The two sides of the nanopapers exhibited different contact angles due to their different surface roughness. For this reason, the contact angles were reported for the smoother side (in contact with air during filtration). The results are presented in Fig. 6a for the neat and grafted nanopapers. It can be seen that after a less than $10 \mathrm{~s}$ time delay, the contact angle stabilizes for the four samples probed at a constant value. Two different cases can be distinguished. Grafting conditions $3 \mathrm{hOv}$ and $1 \mathrm{hOv}$ corresponding to $3 \mathrm{~h}$ and $1 \mathrm{~h}$ reaction time, respectively, with curing in an oven, yielded contact angles comparable $(3 \mathrm{hOv})$ or slightly lower $(\mathrm{hOV})$ than the neat nanopaper around $35^{\circ}$, corresponding to hydrophilic surfaces. For sample NP1h-Sc, however, a contact angle value of about $60^{\circ}$ was 
obtained. This value is significantly higher than that of the neat NP, which reveals that under these conditions the reaction led to some degree of hydrophobization of the surface.
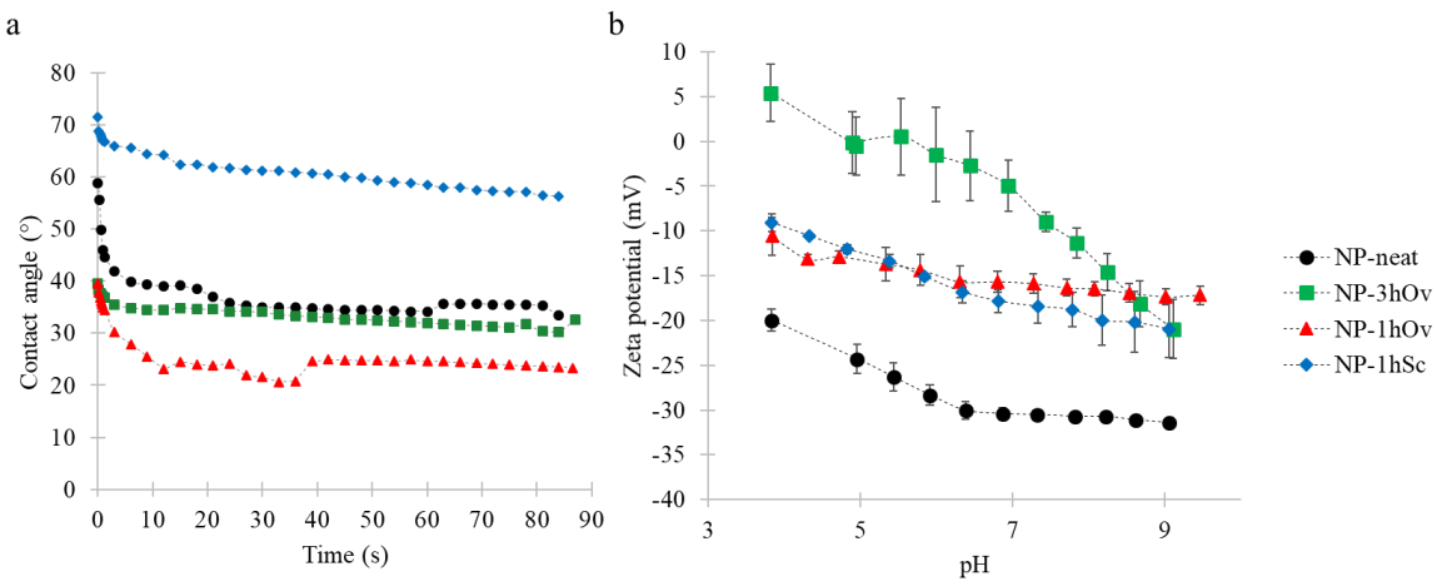

Fig. 6. Contact angle evolution of neat and AHA-P-TMS grafted nanopapers (a) and surface zeta potential evolution with $\mathrm{pH}$ for neat and grafted nanopapers (b).

From these observations, it can be hypothesized on the one hand that the curing step under $\mathrm{scCO}_{2}$ at least partially induces conformation (iv), where the silanes are covalently bound to the surface with the alkyl chain facing outwards. On the other hand, the low contact angles obtained for oven-cured samples is likely to result from the $\mathrm{NH}_{2}$ groups facing outwards. This corresponds to conformations (i) and (ii). However, since low amounts are grafted, conformation (ii) is more likely to happen. In previous works where aminosilanes were grafted on nanocellulose in aqueous medium, the $\mathrm{NH}_{2}$ groups were not facing outwards and polycondensation occurred. Indeed, after grafting of aminosilane on CNF materials, the surfaces became hydrophobic and contact angles increased to $121^{\circ}$ and $114 .^{30,56}$ Similarly, an increase of the initial contact angle from $44^{\circ}$ to $62^{\circ}$ was observed by Yin et al. after grafting of an aminopropyltriethoxysilane on cellulose nanocrystals, which was attributed to the formation of a hydrophobic $3 \mathrm{D}$ network of polycondensed silanes. ${ }^{55}$ Our results combined with these literature 
data could suggest that our reaction protocol in $\mathrm{scCO}_{2}$ prevents polycondensation and that a certain control over the silane conformation is obtained via the curing method. However, further analysis is needed to confirm this hypothesis.

The surface zeta potential was then evaluated for the neat and grafted nanopapers and the results are shown in Fig. 6b. The neat CNF nanopapers exhibited a zeta potential decreasing from -20 to $-31 \mathrm{mV}$ when the $\mathrm{pH}$ increased from 4 to 9 . This result shows that the CNFs are negatively charged due to occasional carboxyl groups on the fiber surface. The grafted nanopapers NP-1hOv and NP-1hSc exhibited similar behaviors but with higher yet still negative values of $c a .-10 \mathrm{mV}$ at $\mathrm{pH} 4$ and $c a .-17 \mathrm{mV}$ and $-21 \mathrm{mV}$, respectively, at $\mathrm{pH} \mathrm{9.} \mathrm{A} \mathrm{positive} \mathrm{zeta}$ potential of $+5 \mathrm{mV}$ was observed for $\mathrm{NP}-3 \mathrm{hOv}$ at $\mathrm{pH} 4$, which decreases to $-21 \mathrm{mV}$ at $\mathrm{pH} 9$ through an isoelectric point around $\mathrm{pH}$ 5-5.5. The increase of zeta potential from negative for the neat $\mathrm{CNF}$ nanopapers to less negative $(\mathrm{NP}-1 \mathrm{hOv}$ and $\mathrm{NP}-1 \mathrm{hSc})$ or even positive (NP-3hOv) values when the $\mathrm{pH}$ is decreased from 9 to 4 confirms the presence of the amino groups at the surface of the grafted nanopapers that undergo protonation when going from alkaline to acidic conditions. A 3 hours grafting in $\mathrm{scCO}_{2}$ followed by curing (NP-3hOv) yields either a higher amount of grafted aminosilane or a higher number of $\mathrm{NH}_{2}$ groups facing outwards than the other conditions probed. The latter conformation is consistent with the low contact angles measured for the NP-3hOv sample. NP-1hOv has a lower zeta potential that NP3hOv and exhibits similar contact angles. This could be the result of a lower number of amino groups grafted compared to the longer reaction of $3 \mathrm{~h}$ for NP-3hOv. Finally, the more negative zeta potential of NP-1hSc compared to NP-3hOv can be attributed to a lower amount of $\mathrm{NH}_{2}$ facing outwards, in agreement with the higher contact angle values measured. In other words, the amines are less accessible for $\mathrm{NP}-1 \mathrm{hSc}$ than for NP-3hOv, and therefore more difficult to protonate. 
In vitro properties assessment. AHA-P-TMS has never been investigated for its antibacterial activity. Therefore, the minimum inhibitory concentrations (MIC) of AHA-P-TMS towards two strains of bacteria was measured. A MIC value of $2.2 \mathrm{mg} \cdot \mathrm{mL}^{-1}$ was found for E. coli. At $1.1 \mathrm{mg} \cdot \mathrm{mL}^{-1}$, a longer lag phase was observed and at $2.2 \mathrm{mg} \cdot \mathrm{mL}^{1}$, no bacterial growth was observed. A lower MIC was observed for $S$. epidermidis, with a value of $1.1 \mathrm{mg} \cdot \mathrm{mL}^{-1}$, which evidences a slightly higher sensitivity of $S$. epidermidis towards AHA-P-TMS. This is consistent with the higher sensitivity of Gram-positive bacteria towards quaternary ammonium compounds (QAC). ${ }^{57}$ The MIC values $(2.2 \mathrm{mg} / \mathrm{mL}$ and $1.1 \mathrm{mg} / \mathrm{mL})$ of AHAPTMS are much higher than the MIC values of typical QAC like benzalkonium chloride $(25.4 \mu \mathrm{g} / \mathrm{mL})$, didecyldimethylammonium chloride $(0.4$ to $500 \mu \mathrm{g} / \mathrm{mL})$ or Bardac $(3.9$ to $31.2 \mu \mathrm{g} / \mathrm{mL}){ }^{58}$ The short alkyl chain of AHA-P-TMS is probably the reason for this weaker MIC. Indeed, in their review, Kwasniewska et al. indicate that the weakest MICs are obtained with alkyl chains from $\mathrm{C} 10$ to $\mathrm{C} 12 .{ }^{57}$ It is worth noting that this test evaluates the "intrinsic" antimicrobial activity of the silane AHA-P-TMS, without any grafting on a surface. Therefore, by performing the test as described, both functions are tested: ammonium and alkoxysilane, which will also be hydrolyzed and three moles of methanol per mole of alkoxysilane will be produced.

Contact antibacterial activity assessment. In order to evaluate the contact activity of the grafted nanopapers, a new test method was investigated. The developed protocol allows for an easy and accurate follow-up of the antibacterial properties of the nanopapers with time. The different neat and grafted nanopapers, immersed in a suspension of bacteria, were incubated in optimal conditions for bacterial growth. The bacteria were brought in contact with the nanopapers by vigorous shaking. To assess the antibacterial effect of the grafted nanopapers in 
liquid, the optical density was monitored over time as illustrated in Fig. 7a and $\mathbf{b}$ and results are shown in Fig. 7c and d.

a

b
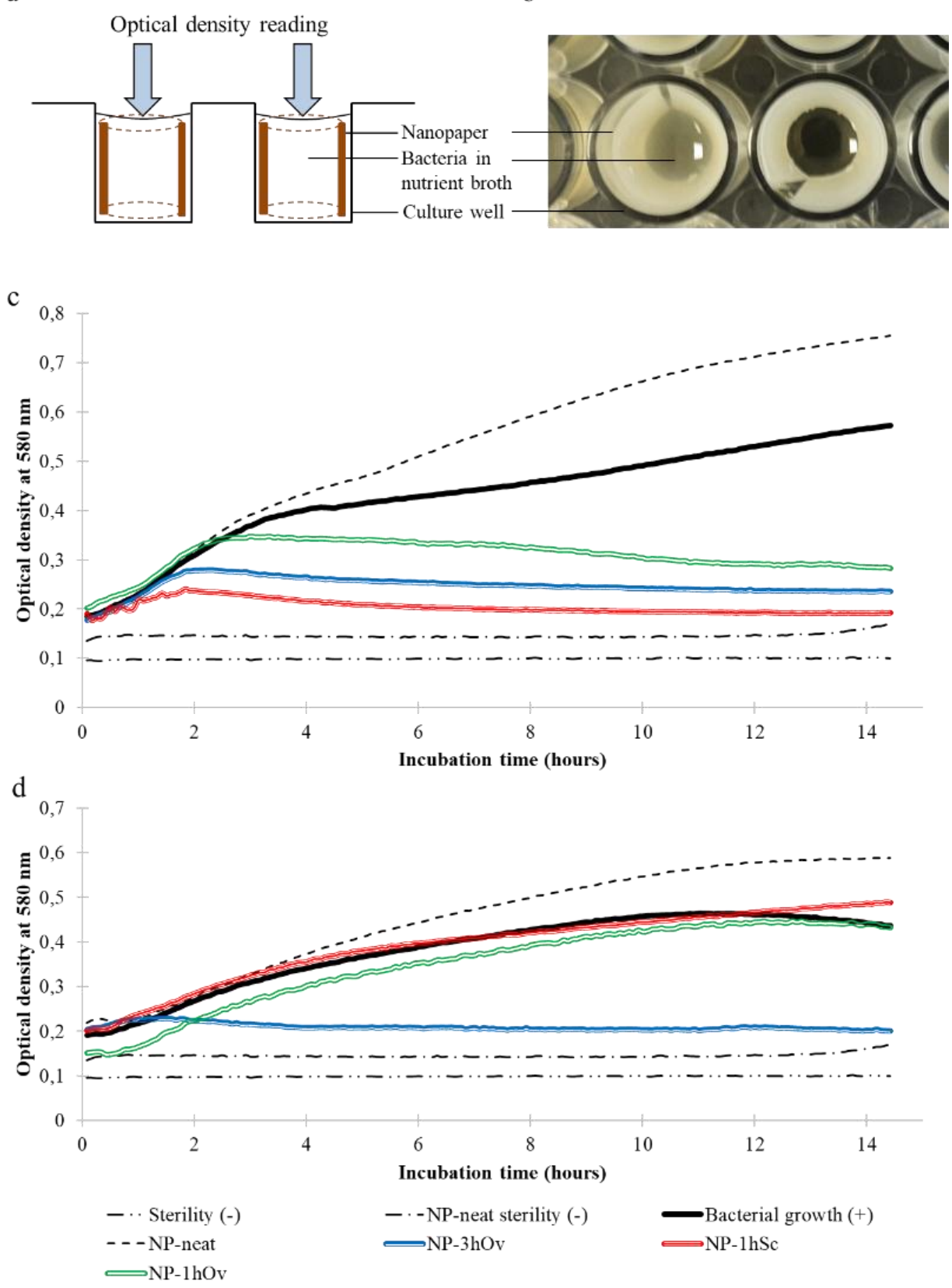

Fig. 7. Optical density reading scheme (a) and photograph of the set-up showing bacterial growth in contact with a neat (left) and grafted (right) nanopaper (b) and antibacterial activity assessment of nanopapers in liquid conditions against E. coli (c) and S. epidermidis (d). Sterility 
negative control contains broth only. NP-neat sterility negative control contains neat NP and broth. Bacterial growth positive control contains bacteria and broth without NP.

A negative control with only the nutrient broth and a positive control with the bacteria (E. coli or S. epidermidis) in nutrient broth were performed to validate the experiment. The sterility negative control confirms the absence of contamination during the experiment by a low and steady optical density and the positive control confirms the growth of both bacteria by the increase in optical density with time. Nanopapers immersed in a sterile nutrient broth (NP-neat sterility) were used to establish the impact of the nanopaper on the optical density. A slightly higher optical density compared to the sterility control was observed. No bacterial growth is noticed, however, by the end of the 15 hours of incubation, an optical density increase was observed, which is likely to attest the beginning of contamination growth. For both bacteria, the presence of non-grafted nanopapers enhances bacterial growth, as illustrated by an increase in optical density compared to the positive control. This may be the result of a higher amount of nutrients provided by the nanocellulose substrate and the possible presence of glucose. Indeed, the cellulose nanofibrils used for the preparation of nanopapers are obtained after a combination of enzymatic and mechanical treatments prone to liberate glucose units or small cellulose oligomers, which will be available for bacterial growth.

By looking at the evolution of the optical density with time for E. coli, after 15 hours of incubation, the final optical density decreased from 0.75 for the NP-neat to $0.24,0.28$ and 0.19 for NP-3hOv, NP-1hOv and NP-1hSc, respectively. The nanopapers grafted with AHA-P-TMS under the three different conditions therefore exhibit antibacterial activity against $E$. coli. The slight differences observed for the different nanopapers are a result of differences observed at the beginning of incubation. At the early stage of incubation, the optical density for each condition 
follows the same slope. The slope break occurs at different times for the different nanopapers in the following order: NP-1hSc $<\mathrm{NP}-3 \mathrm{hOv}<\mathrm{NP}-1 \mathrm{hOv}$. The longer antibacterial growth observed in presence of NP-1hOv can be attributed to a lower amount of aminosilane grafted, which delays the antibacterial activity.

Contrary to what has been observed for AHA-P-TMS in solution when establishing the MIC of the aminosilane, a different behavior, with a lower activity against the Gram-positive bacteria is observed when the silane is grafted. Indeed, against S. epidermidis, only NP-3hOv exhibits a low optical density attesting antibacterial activity. The optical density of the bacterial suspensions in contact with NP-1hSc and NP-1hOv are slightly lower than the one of the neat nanopapers, however, no bactericidal effect was observed. The antibacterial activity of NP-3hOv may result from a higher grafted amount of aminosilane, sufficient to kill bacteria, and a favorable organization, with more amino-groups available, as suggested by the lower contact angle than NP-1hSc and higher zeta potential observed in acidic conditions.

These results attest the antibacterial property of the grafted nanopapers. The conformation of the silane (alkyl chain or amino groups facing outwards) does not seem to play such a crucial role against the Gram-negative E. coli. High activity is observed for the three conformations against $E$. coli, and only NP-3hOv exhibit activity against $S$. epidermidis. The grafting amount is similar for NP-3hOv and NP-1hSc, hence the conformation plays an important role against $S$. epidermidis and a conformation of the amino groups facing outwards is required to exhibit antibacterial activity against the Gram-positive bacteria.

A leaching assay was performed to detect whether the aminosilane could be released. This experiment should therefore give information on whether a fraction of AHA-P-TMS is not covalently grafted but only adsorbed. The neat and grafted materials were placed in a nutritive 
releasing solution for 24 hours at $37^{\circ} \mathrm{C}$ under stirring. This solution was then inoculated with $E$. coli and used as a growth media. After 24 hours of incubation, the bacterial population was evaluated by measuring the optical density of the medium. The results are presented in Fig. 8. When no bacteria are present, the optical density is low with a value of 0.09 for the sterile broth. When a suspension of bacteria added with an antibiotic (ciprofloxacin) is considered, a slightly higher value of 0.11 is observed, due to the residual dead bacteria. The growth control (E. coli in nutrient broth) shows a high optical density of 0.44 , which results from a normal bacterial proliferation.

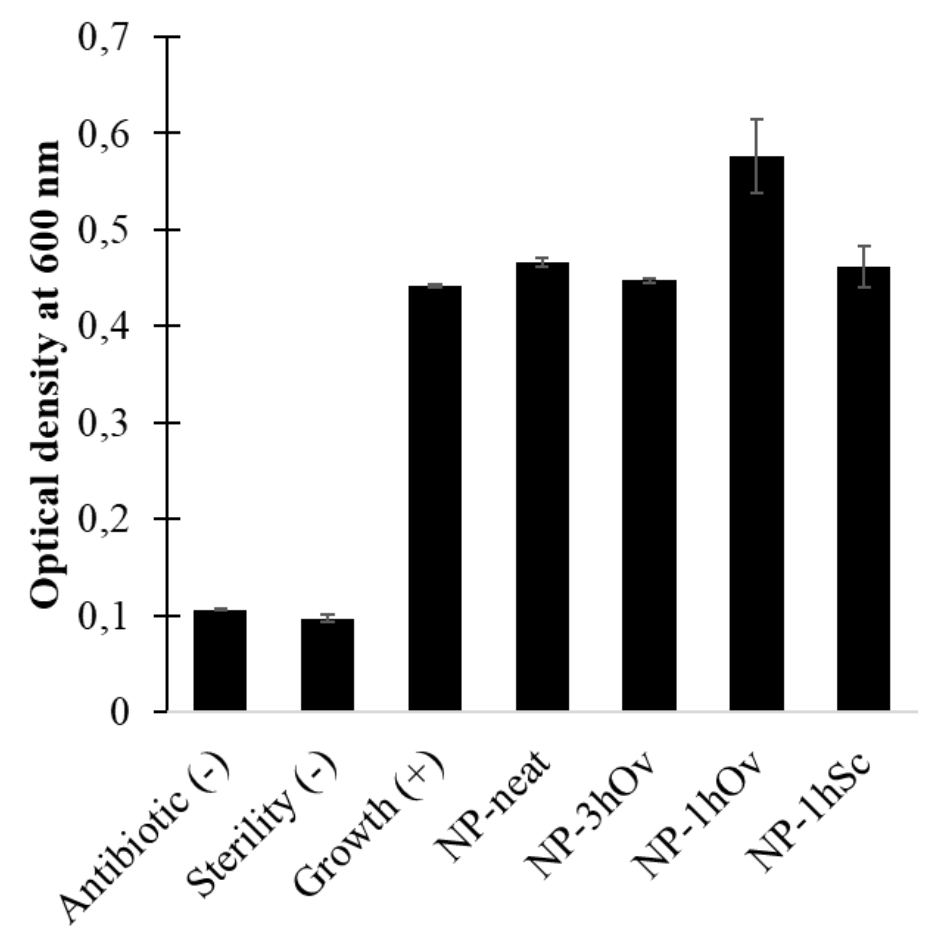

Fig. 8. E.coli bacterial growth monitoring from optical density measurement in leaching solution of neat and grafted materials.

When the bacteria were growing in the releasing medium of the neat nanopaper, the optical density was of 0.46 , indicating that the unmodified sample does not exhibit any intrinsic antibacterial activity. The releasing media of NP-3hOv, NP-1hOv and NP-1hSc allow good 
bacterial proliferation, as testified by the optical densities of $0.45,0.58$ and 0.46 , respectively. These releasing solutions do therefore not exhibit any antibacterial effect, which shows that the aminosilane was not released from the functionalized nanopapers or at least not in sufficient quantity to cause antibacterial activity. This result is an indirect proof of the covalent grafting of the AHA-P-TMS onto the nanopapers. Consequently, it can be established that the functionalized nanopapers antimicrobial activity, as observed on the curves in Figure 7, is the result of contact killing and no release of active molecule is observed. This is essential with regard to the application as it proves that the nanopaper would be active without decreasing its antimicrobial activity for a long period.

Cytotoxicity assay. The CNF materials exhibit antibacterial properties and in order to be used as biomedical devices, in contact with tissues and cells, they need to exhibit biocompatibility. Cytotoxicity is often the first test performed as it gives a reliable indication of the tissue cells in vitro response to the tested materials. ${ }^{59}$

First, the cytotoxicity of AHA-P-TMS in solution was evaluated and a decrease in fibroblasts cell viability was observed from $20 \mu \mathrm{g} \cdot \mathrm{mL}^{-1}$ of aminosilane (Fig. 9a). The material cytotoxicity was then evaluated in direct and indirect conditions and the results are shown in Fig. $\mathbf{9 b}$.

a

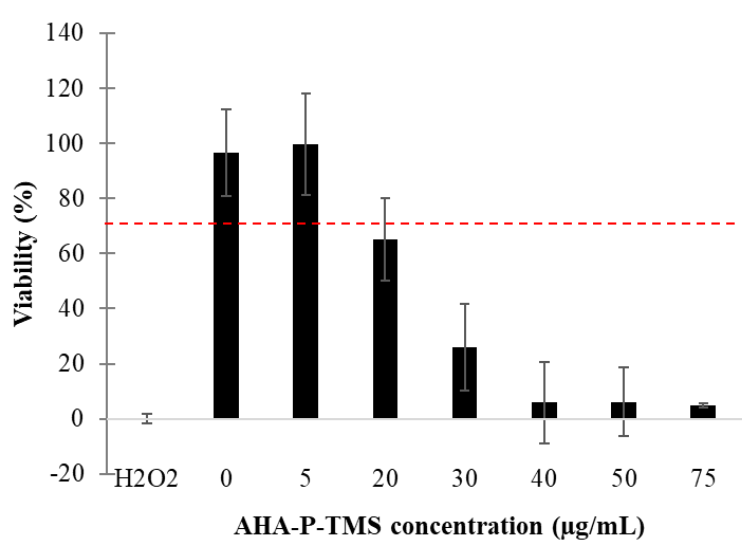

b
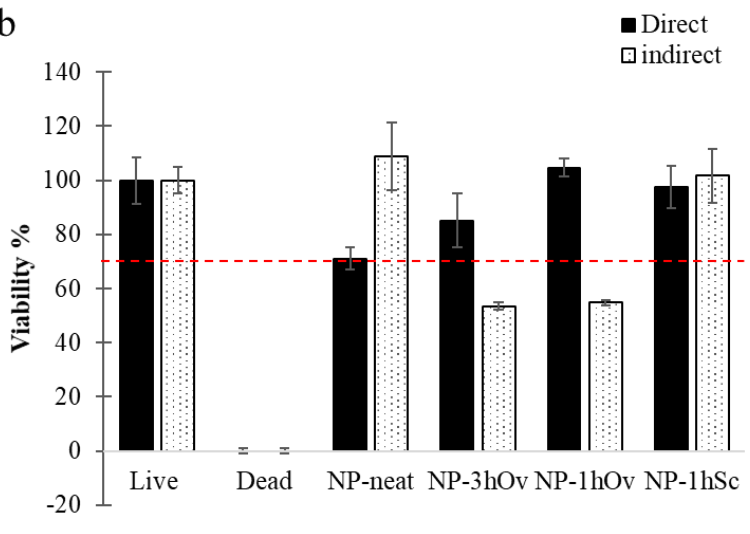
Fig. 9. Cell viability in presence of AHA-P-TMS (a) and of neat and grafted nanopapers structures (b) Red dotted line indicates the limit of cytotoxicity.

Positive (live) and negative (dead) controls were used to scale the cell viability in conditions of cells alone and cultured in the presence of hydrogen peroxide, respectively. The norm EN ISO 10993-5:200960 states that a material is considered cytotoxic when the cell viability is reduced by more than $30 \%$. From the direct condition assessment, the neat and grafted nanopapers exhibit cell viability higher than $70 \%$. This result points out the non-toxicity of the neat and functionalized materials. Indirect assessment of the toxicity shows a different behavior with a good cell viability of 109 and $102 \%$ for the neat nanopaper and NP-1hSc respectively. But on the contrary, this mode of assessment reveals the toxicity of the NP-3hOv and NP- $1 \mathrm{hOv}$ releasing media, as cell viability decreases up to 54 and $55 \%$, respectively.

No or reduced toxicity was expected from the indirect test if the aminosilane had been covalently bound. The toxicity observed for NP-3hOv and NP-1hOv and the high cell viability measured for NP-1hSc samples could indicate a more efficient covalent grafting during the $\mathrm{scCO}_{2}$ curing step. However, it is important to note that for each sample no strong cytotoxicity was observed. Furthermore, the cells cultured in wells are more sensitive than in vivo, where lower toxicity would be expected.

\section{CONCLUSIONS}

In this study, the AHA-P-TMS was grafted on the surface of cellulose nanofibril-based materials using an innovative and sustainable approach in supercritical carbon dioxide. Reaction time and curing steps were varied and their influence on the grafting efficiency was evaluated.

The XPS analysis, contact angle and surface zeta potential measurements confirmed the presence of AHA-P-TMS at low concentration at the surface of nanopapers. The curing step 
performed in $\mathrm{scCO}_{2}$ yielded grafted CNF structures with a layer of aminosilane showing less accessible amino groups (NP-1hSc), with alkyl chains probably facing outwards. This property did not hinder its antibacterial properties, and the materials exhibited good antibacterial activity towards Gram-negative E. coli and Gram-positive S. epidermidis bacteria. For S. epidermidis, however, results tend to prove that the silane conformation matters and that antibacterial activity can only be reached when a sufficient amount of silane with amino groups pointing outwards is obtained. For E. coli, the activity mostly depends on the amount grafted, irrespective of the conformation. The non-leaching behavior of the grafted nanopapers was assessed and confirmed that the aminosilane was grafted and could not be released in the medium, showing that the mode of activity is contact killing. The cytotoxicity of nanopapers towards fibroblasts was studied by investigating the cell viability in contact with the neat and grafted materials and no or low toxicity was revealed. It should be noted that a possible advantage of having a limited amount of silanes grafted to the surface is to impart antibacterial properties to the materials while retaining the mechanical properties of the materials and avoiding potential silane toxicity problems.

These newly designed materials could be used for their antibacterial activity in the biomedical field. Perspectives for topical administration and wound dressing design could be considered. This innovative and versatile grafting method could be applied to different oxide substrates and bio-based polysaccharides. The wide class of silanes reagents enables for a large range of functionalization and applications.

\section{AUTHOR INFORMATION}

\section{Corresponding Author}


*Guillaume Nonglaton - Univ. Grenoble Alpes, CEA, LETI, F-38054 Grenoble, France; Email: guillaume.nonglaton@cea.fr

\section{Present Addresses}

${ }^{¥}$ Clémentine Darpentigny - Univ. Grenoble Alpes, CNRS, Grenoble INP, LGP2, Grenoble, France; Email: clementine.darpentigny@grenoble-inp.fr

${ }^{\#}$ Julien Bras - Nestlé research Center, Lausanne, 1000, Suisse: Email: julien.bras@rd.nestle.com

\section{Author Contributions}

The manuscript was written through contributions of all authors. All authors have given approval to the final version of the manuscript.

\section{Funding Sources}

This work was supported by a grant from Labex ARCANE (ANR-11-LABX-0003-01) and CBH-EUR-GS (ANR-17-EURE-0003) and supported by the "Investissement d'Avenir" program Glyco@Alps (ANR-15-IDEX-02). This research was made possible thanks to the facilities of the TekLiCell platform funded by the Région Rhône-Alpes (ERDF: European regional development fund). LGP2 is part of the LabEx Tec 21 (Investissements d'Avenir-Grant Agreement No. ANR-11- LABX-0030) and of PolyNat Carnot Institute (Investissements d'Avenir-Grant Agreement No. ANR-16-CARN-0025-01).

\section{ACKNOWLEDGMENT}

The authors acknowledge the Borregaard company for providing CNF materials and thank Bertine Khelifi for the microscopy images.

\section{ABBREVIATIONS}


AHA-P-TMS, $N$-(6-aminohexyl)aminopropyltrimethoxysilane; CNF, cellulose nanofibril; MIC, minimum inhibitory concentration; $\mathrm{NP}$, nanopaper; PBS, phosphate buffered saline; $\mathrm{scCO}_{2}$, supercritical carbon dioxide; XPS, X-ray photoelectron spectroscopy.

\section{REFERENCES}

1. Abitbol, T.; Rivkin, A.; Cao, Y.; Nevo, Y.; Abraham, E.; Ben-Shalom, T.; Lapidot, S.; Shoseyov, O., Nanocellulose, a tiny fiber with huge applications. Curr. Opin. Biotechnol. 2016, 39, 76-88.

2. Nechyporchuk, O.; Belgacem, M. N.; Bras, J., Production of cellulose nanofibrils: A review of recent advances. Ind. Crops Prod. 2016, 93, 2-25.

3. Foster, E. J.; Moon, R. J.; Agarwal, U. P.; Bortner, M. J.; Bras, J.; Camarero-Espinosa, S.; Chan, K. J.; Clift, M. J. D.; Cranston, E. D.; Eichhorn, S. J.; Fox, D. M.; Hamad, W. Y.; Heux, L.; Jean, B.; Korey, M.; Nieh, W.; Ong, K. J.; Reid, M. S.; Renneckar, S.; Roberts, R.; Shatkin, J. A.; Simonsen, J.; Stinson-Bagby, K.; Wanasekara, N.; Youngblood, J., Current characterization methods for cellulose nanomaterials. Chem. Soc. Rev. 2018, 47 (8), 2609-2679.

4. Shi, Z.; Phillips, G. O.; Yang, G., Nanocellulose electroconductive composites. Nanoscale 2013, 5 (8), 3194-3201.

5. Hoeng, F.; Denneulin, A.; Bras, J., Use of nanocellulose in printed electronics: a review. Nanoscale 2016, 8 (27), 13131-13154.

6. Bardet, R.; Bras, J., Cellulose Nanofibers and Their Use in Paper Industry. In Handbook of Green Materials, pp 207-232.

7. Boufi, S.; González, I.; Delgado-Aguilar, M.; Tarrès, Q.; Pèlach, M. À.; Mutjé, P., Nanofibrillated cellulose as an additive in papermaking process: A review. Carbohydr. Polym. 2016, 154, 151-166.

8. Jorfi, M.; Foster, E. J., Recent advances in nanocellulose for biomedical applications. $J$. Appl. Polym. Sci. 2015, 132 (14), 41719-41738.

9. Lin, N.; Dufresne, A., Nanocellulose in biomedicine: Current status and future prospect. Eur. Polym. J. 2014, 59, 302-325.

10. Aduba Jr., D. C.; An, S.-S.; Selders, G. S.; Wang, J.; Andrew Yeudall, W.; Bowlin, G. L.; Kitten, T.; Yang, H., Fabrication, characterization, and in vitro evaluation of silver-containing arabinoxylan foams as antimicrobial wound dressing. J. Biomed. Mater. Res. A 2016, 104 (10), 2456-2465.

11. Alexandrescu, L.; Syverud, K.; Gatti, A.; Chinga-Carrasco, G., Cytotoxicity tests of cellulose nanofibril-based structures. Cellulose 2013, 20 (4), 1765-1775.

12. Rashad, A.; Suliman, S.; Mustafa, M.; Pedersen, T. Ø.; Campodoni, E.; Sandri, M.; Syverud, K.; Mustafa, K., Inflammatory responses and tissue reactions to wood-Based nanocellulose scaffolds. Mater. Sci. Eng. C 2019, 97, 208-221.

13. Darpentigny, C.; Marcoux, P. R.; Menneteau, M.; Michel, B.; Ricoul, F.; Jean, B.; Bras, J.; Nonglaton, G., Antimicrobial Cellulose Nanofibril Porous Materials Obtained by Supercritical Impregnation of Thymol. ACS Appl. Bio Mater. 2020, 3 (5), 2965-2975.

14. Rol, F.; Belgacem, M. N.; Gandini, A.; Bras, J., Recent advances in surface-modified cellulose nanofibrils. Prog. Polym. Sci. 2019, 88, 241-264. 
15. Eyley, S.; Thielemans, W., Surface modification of cellulose nanocrystals. Nanoscale 2014, 6 (14), 7764-7779.

16. Habibi, Y., Key advances in the chemical modification of nanocelluloses. Chem. Soc. Rev. 2014, 43 (5), 1519-1542.

17. Missoum, K.; Belgacem, M. N.; Bras, J., Nanofibrillated cellulose surface modification: A review. Materials 2013, 6 (5), 1745-1766.

18. Cassano, R.; Trombino, S.; Ferrarelli, T.; Nicoletta, F. P.; Mauro, M. V.; Giraldi, C.; Picci, N., Hemp fiber (Cannabis sativa L.) derivatives with antibacterial and chelating properties. Cellulose 2013, 20 (1), 547-557.

19. Caldeira, E.; Piskin, E.; Granadeiro, L.; Silva, F.; Gouveia, I. C., Biofunctionalization of cellulosic fibres with 1-cysteine: Assessment of antibacterial properties and mechanism of action against Staphylococcus aureus and Klebsiella pneumoniae. J. Biotechnol. 2013, 168 (4), 426435.

20. Saini, S.; Belgacem, N.; Mendes, J.; Elegir, G.; Bras, J., Contact Antimicrobial Surface Obtained by Chemical Grafting of Microfibrillated Cellulose in Aqueous Solution Limiting Antibiotic Release. ACS Appl. Mater. Interfaces 2015, 7 (32), 18076-18085.

21. Littunen, K.; Snoei de Castro, J.; Samoylenko, A.; Xu, Q.; Quaggin, S.; Vainio, S.; Seppälä, J., Synthesis of cationized nanofibrillated cellulose and its antimicrobial properties. Eur. Polym. J. 2016, 75, 116-124.

22. Saini, S.; Sillard, C.; Naceur Belgacem, M.; Bras, J., Nisin anchored cellulose nanofibers for long term antimicrobial active food packaging. Rsc Adv 2016, 6 (15), 12422-12430.

23. Hassanpour, A.; Asghari, S.; Lakouraj, M. M., Synthesis, characterization and antibacterial evaluation of nanofibrillated cellulose grafted by a novel quinolinium silane salt. Rsc Adv 2017, 7 (39), 23907-23916.

24. Fernandes, S. C. M.; Sadocco, P.; Alonso-Varona, A.; Palomares, T.; Eceiza, A.; Silvestre, A. J. D.; Mondragon, I.; Freire, C. S. R., Bioinspired Antimicrobial and Biocompatible Bacterial Cellulose Membranes Obtained by Surface Functionalization with Aminoalkyl Groups. ACS Appl. Mater. Interfaces 2013, 5 (8), 3290-3297.

25. Saini, S.; Belgacem, M. N.; Salon, M.-C. B.; Bras, J., Non leaching biomimetic antimicrobial surfaces via surface functionalisation of cellulose nanofibers with aminosilane. Cellulose 2016, 23 (1), 795-810.

26. Kabara, J. J.; Conley, A. J.; Truant, J. P., Relationship of chemical structure and antimicrobial activity of alkyl amides and amines. Antimicrob. Agents Chemother. 1972, 2 (6), 492-498.

27. Goy, R. C.; Morais, S. T. B.; Assis, O. B. G., Evaluation of the antimicrobial activity of chitosan and its quaternized derivative on E. coli and S. aureus growth. Rev. Bras. Farmacogn. 2016, $26(1), 122-127$.

28. He, W.; Zhang, Y.; Li, J.; Gao, Y.; Luo, F.; Tan, H.; Wang, K.; Fu, Q., A Novel Surface Structure Consisting of Contact-active Antibacterial Upper-layer and Antifouling Sub-layer Derived from Gemini Quaternary Ammonium Salt Polyurethanes. Sci. Rep. 2016, 6 (1), 32140.

29. Kim, C. H.; Choi, J. W.; Chun, H. J.; Choi, K. S., Synthesis of chitosan derivatives with quaternary ammonium salt and their antibacterial activity. Polym. Bull. 1997, 38 (4), 387-393.

30. Saini, S.; Belgacem, M. N.; Bras, J., Effect of variable aminoalkyl chains on chemical grafting of cellulose nanofiber and their antimicrobial activity. Mater. Sci. Eng. C 2017, 75, 760768. 
31. Reverdy, C. n. Industrial applications of functional nanocelluloses. Ph.D. Thesis, Université Grenoble Alpes, Grenoble, 2017.

32. Chantereau, G.; Brown, N.; Dourges, M.-A.; Freire, C. S. R.; Silvestre, A. J. D.; Sebe, G.; Coma, V., Silylation of bacterial cellulose to design membranes with intrinsic anti-bacterial properties. Carbohydr. Polym. 2019, 220, 71-78.

33. Yuan, X.; Wolf, N.; Mayer, D.; Offenha?usser, A.; Wo?rdenweber, R., Vapor-Phase Deposition and Electronic Characterization of 3-Aminopropyltriethoxysilane Self-Assembled Monolayers on Silicon Dioxide. Langmuir 2019, 35 (25), 8183-8190.

34. Zhang, F.; Sautter, K.; Larsen, A. M.; Findley, D. A.; Davis, R. C.; Samha, H.; Linford, M. R., Chemical Vapor Deposition of Three Aminosilanes on Silicon Dioxide: Surface Characterization, Stability, Effects of Silane Concentration, and Cyanine Dye Adsorption. Langmuir 2010, 26 (18), 14648-14654.

35. Katsikogianni, M. G.; Missirlis, Y. F., Interactions of bacteria with specific biomaterial surface chemistries under flow conditions. Acta Biomater. 2010, 6 (3), 1107-1118.

36. Katsikogianni, M. G.; Missirlis, Y. F., Bacterial adhesion onto materials with specific surface chemistries under flow conditions. J. Mater. Sci. Mater. Med. 2010, 21 (3), 963-968.

37. Yadav, A. R.; Sriram, R.; Carter, J. A.; Miller, B. L., Comparative study of solutionphase and vapor-phase deposition of aminosilanes on silicon dioxide surfaces. Mater. Sci. Eng. C 2014, 35 (0), 283-290.

38. McCool, B.; Tripp, C. P., Inaccessible hydroxyl groups on silica are accessible in supercritical $\mathrm{CO}_{2}$. J. Phys. Chem. B 2005, 109 (18), 8914-8919.

39. Fu, H.; Coelho, L. A. F.; Matthews, M. A., Diffusion coefficients of model contaminants in dense $\mathrm{CO}_{2}$. J. Supercrit. Fluids 2000, 18 (2), 141-155.

40. Zhou, J.; Lu, X.; Wang, Y.; Shi, J., Molecular dynamics investigation on the infinite dilute diffusion coefficients of organic compounds in supercritical carbon dioxide. Fluid Phase Equilib. 2000, 172 (2), 279-291.

41. Duan, Y.; Jana, S. C.; Lama, B.; Espe, M. P., Hydrophobic silica aerogels by silylation. $J$. Non-Cryst. Solids 2016, 437, 26-33.

42. Sanli, D.; Erkey, C., Silylation from supercritical carbon dioxide: a powerful technique for modification of surfaces. J. Mater. Sci. 2015, 50 (22), 7159-7181.

43. Rull, J.; Nonglaton, G.; Costa, G.; Fontelaye, C.; Marchi-Delapierre, C.; Menage, S.; Marchand, G., Functionalization of silicon oxide using supercritical fluid deposition of 3,4epoxybutyltrimethoxysilane for the immobilization of amino-modified oligonucleotide. Appl. Surf. Sci. 2015, 354, 285-297.

44. Zhu, M.; Lerum, M. Z.; Chen, W., How To Prepare Reproducible, Homogeneous, and Hydrolytically Stable Aminosilane-Derived Layers on Silica. Langmuir 2012, 28 (1), 416-423.

45. Dong, W.-H.; Liu, J.-X.; Mou, X.-J.; Liu, G.-S.; Huang, X.-W.; Yan, X.; Ning, X.; Russell, S. J.; Long, Y.-Z., Performance of polyvinyl pyrrolidone-isatis root antibacterial wound dressings produced in situ by handheld electrospinner. Colloids Surf. B. Biointerfaces 2020, 188, 110766.

46. Bacakova, L.; Pajorova, J.; Bacakova, M.; Skogberg, A.; Kallio, P.; Kolarova, K.; Svorcik, V., Versatile Application of Nanocellulose: From Industry to Skin Tissue Engineering and Wound Healing. Nanomaterials 2019, 9 (2), 164.

47. EUCAST, Disk Diffusion Method for Antimicrobial Susceptibility Testing, v. 8.0. 2020. 
48. Darpentigny, C.; Molina-Boisseau, S.; Nonglaton, G.; Bras, J.; Jean, B., Ice-templated freeze-dried cryogels from tunicate cellulose nanocrystals with high specific surface area and anisotropic morphological and mechanical properties. Cellulose 2020, 27 (1), 233-247.

49. Dijkstra, Z. J.; Doornbos, A. R.; Weyten, H.; Ernsting, J. M.; Elsevier, C. J.; Keurentjes, J. T. F., Formation of carbamic acid in organic solvents and in supercritical carbon dioxide. $J$. Supercrit. Fluids 2007, 41 (1), 109-114.

50. Abdelmouleh, M.; Boufi, S.; Belgacem, M. N.; Dufresne, A.; Gandini, A., Modification of cellulose fibers with functionalized silanes: Effect of the fiber treatment on the mechanical performances of cellulose-thermoset composites. J. Appl. Polym. Sci. 2005, 98 (3), 974-984.

51. Domingo, C.; Loste, E.; Fraile, J., Grafting of trialkoxysilane on the surface of nanoparticles by conventional wet alcoholic and supercritical carbon dioxide deposition methods. J. Supercrit. Fluids 2006, 37 (1), 72-86.

52. de Monredon-Senani, S. Interaction Organosilanes / Silice de précipitationDu milieu hydroalcoolique au milieu aqueux. Ph.D. Thesis, Université Pierre et Marie Curie - Paris VI, 2004.

53. de Monredon, S.; Pottier, A.; Maquet, J.; Babonneau, F.; Sanchez, C., Characterisation of the grafting of (3-aminoethyl)aminopropyltrimethoxy silane on precipitated silica. New J. Chem. 2006, 30 (5), 797-802.

54. Marzorati, S.; Ragg, E. M.; Longhi, M.; Formaro, L., Low-temperature intermediates to oxygen reduction reaction catalysts based on amine-modified metal-loaded carbons. An XPS and ss-NMR investigation. Mater. Chem. Phys. 2015, 162, 234-243.

55. Yin, Y.; Ma, J.; Tian, X.; Jiang, X.; Wang, H.; Gao, W., Cellulose nanocrystals functionalized with amino-silane and epoxy-poly(ethylene glycol) for reinforcement and flexibilization of poly(lactic acid): material preparation and compatibility mechanism. Cellulose 2018, 25 (11), 6447-6463.

56. Reverdy, C.; Belgacem, N.; Moghaddam, M. S.; Sundin, M.; Swerin, A.; Bras, J., Onestep superhydrophobic coating using hydrophobized cellulose nanofibrils. Colloids Surf. Physicochem. Eng. Aspects 2018, 544, 152-158.

57. Kwaśniewska, D.; Chen, Y.-L.; Wieczorek, D., Biological Activity of Quaternary Ammonium Salts and Their Derivatives. Pathogens 2020, 9 (6), 459.

58. Buffet-Bataillon, S.; Tattevin, P.; Bonnaure-Mallet, M.; Jolivet-Gougeon, A., Emergence of resistance to antibacterial agents: the role of quaternary ammonium compounds - a critical review. Int. J. Antimicrob. Agents 2012, 39 (5), 381-389.

59. Li, W.; Zhou, J.; Xu, Y., Study of the in vitro cytotoxicity testing of medical devices. Biomed. Rep. 2015, 3 (5), 617-620. 